International Journal of Advanced Biological and Biomedical Research Available online at http:www.ijabbr.com

Volume 8, Issue 1 (2020) pp. 1-8

DOI: 10.33945/SAMI/IJABBR.2020.1.1

Original Article

\title{
Efficacy Evaluation of Tribenuron Methyl Herbicide by Using Different Adjuvants for Common Lambsquarters (Chenopodium album L.) Control
}

\author{
Mohammad Mehdizadeh1,*, Zoleikha Mehdizadeh², Zahra Baghaeifar ${ }^{2}$ \\ 1Department of Agronomy and Plant Breeding, Faculty of Agriculture and Natural \\ Resources, University of Mohaghegh Ardabili, Ardabil, Iran \\ ${ }^{2}$ Department of Biology, Payame Noor University (PNU), P.Obox, 1935-4697, Tehran, Iran \\ *Corresponding Author E-mail: mehdizade.mohammad@gmail.com
}

Received: 14 June 2019, Revised: 7 July 2019, Accepted: 9 August 2019

\begin{abstract}
Environmental risks resulting from the increasing application of chemical herbicides have raised many concerns about human health and the safety of agro ecosystems and environment. Hence, it is very important to find practical and effective methods for reducing the use of pesticides in environment as well as the increasing the efficiency of these compounds. Addition of adjuvants to spray solutions could be considered as one of these methods. Greenhouse studies were conducted using a complete randomized design with a factorial arrangement during 2015-2016 to evaluate the impact of different adjuvants (citogate, canola oil, and castor oil) at concentrations of 0.1 and $0.2(\% \mathrm{v} / \mathrm{v})$ with $5,10,20,30$ and $40 \mathrm{~g}$ a.i. ha ${ }^{-1}$ of tribenuron methyl herbicide to control common lambsquarters. Results showed that all applied adjuvants enhanced the efficacy of tribenuron methyl in decreasing the biomass of common lambsquarters. Efficacy of this herbicide increased with enhancing its concentrations. The required dose of herbicide to give 50 per cent common lambsquarters control $\left(\mathrm{ED}_{50}\right)$ for no adjuvant, citogate, castor oil, and canola oil application $(0.2(\% \mathrm{v} / \mathrm{v}))$ was $21.24,11.48,11.65$, and $11.81 \mathrm{~g}$ a.i. ha ${ }^{-1}$, respectively. Totally the application of citogate and canola oil had the highest and the lowest impact on tribenuron methyl performance to control of common lambsquarters respectively. Also, the Relative Potency values were significantly increased when adjuvants were added to this herbicide. The results revealed that the use of citogate and vegetable oils can increase the efficiency tribenuron methyl, and reduce the application rate of this herbicide in agro ecosystems.
\end{abstract}

Key words: Adjuvants, Citogate, $\mathrm{ED}_{50}$, Vegetable oils.

\section{Introduction}

Herbicides is one of the most important methods for weed management in agricultural production systems (Powles and Yu, 2010; Widayat et al., 2019). Tribenuron methyl is belongs to sulfonylureas herbicides, known as a selective post emergence herbicide rapidly absorbed and translocated through the plants and inhibit the biosynthesis of the essential amino acids including valine, leucine, and isoleucine (Lian et al., 2019). This classes of herbicides are one of 
the most important and effective herbicides for weed management in many countries (Kraehmer et al., 2014). High selective pressure imposed by sulfonylureas herbicides might lead to the induction of resistance in different weeds (Khammassi et al., 2018). However the environmental issues and negative effects of these herbicides on non-target plants could be considered (Mehdizadeh, 2016; Mehdizadeh et al., 2016; Mehdizadeh and Gholami-Abadan, 2018). Therefore, finding the effective methods such as non-chemical weed management strategies (Asad et al., 2019), the use of bioherbicides (Singh and Pandey, 2019), as well as the application of different surfactants to reduce the negative effects of these chemical compounds should be considered. The use of adjuvants and specially vegetable oils adjuvants is a practical method to enhance the efficiency of a mixture of metsulfuron methyl and sulfosulfuron herbicide to control little seed canary grass (Mehdizadeh and Izadi Darbandi, 2015). The proper application of adjuvants to herbicides tank mixture can improve the biological activity of herbicide molecules, the efficiency of the spray solution, the economic aspects of herbicide application, and also decrease the application rates of herbicides (Sharma and Singh, 2000; Underwood, 2000). However, there are many different types of adjuvants and based on some factors including herbicide classes, plant species, and environmental conditions, the response to the presence of adjuvants in spray solution could be evaluated. Reduction of surface tension of spray solution, the bioavailability of the herbicide molecules and improve the distribution pattern and contact angle of herbicides, as well as the increase of droplets spread on plant surface and enhance the foliar activity of post-emergence herbicides could be achieved by addition of adjuvants to herbicides solution (Rashed-Mohassel et al., 2009; Calore et al., 2015; Kočárek et al., 2018; Niedobová et al., 2019). However the adjuvant efficiency depends on the herbicide, adjuvant and target plant relationships (Bunting et al., 2004). (Marcinkowska et al., 2018) found that the addition of bioionic liquids as adjuvants to the spray solution significantly reduced the surface tension and contact angle of spray droplets and increased the area of sulfonylurea herbicide deposit on the leaf surface. (Rizwan et al., 2018) reported an increased efficacy of isoproturon+tribenuron for control of little seed canary grass and field bindweed by addition of minerals and vegetable oil adjuvants. One of the most frequent dicotyledonous weeds with the great economic importance is common lambsquarters (Chenopodium album L.) (Keller et al., 2014). Therefore, this study was conducted to evaluate the ability of three different adjuvants on increasing the performance of tribenuron methyl against this weed.

\section{Materials and methods}

The seeds of common lambsquarters (Chenopodium album L.) were collected from plants in the fields and preserved at $4{ }^{\circ} \mathrm{C}$. To increase seed germination, the seeds were placed in petri dishes on a single layer of Whatman filter paper No. 1 containing $100 \mathrm{mg} / \mathrm{L}^{-1}$ of ethylene for breaking dormancy (Saini et al., 1986). After germination, ten healthy seedlings were selected and planted at proper depth in $1.5 \mathrm{~L}$ plastic pots $(12 \mathrm{~cm}$ diameter) that were filled with an equal mixture of sand, clay loam soil and vermiculate. The pots were placed in a greenhouse with a light/dark period of $16 / 8$ hours at $25 / 15^{\circ} \mathrm{C}$. A lamp was used to supply additional light and extend the day length. The plants were irrigated every two days and thinned to five plants per pot at two-leaf stage.

Experiment was laid out in complete randomized design with a factorial arrangement of treatments and three replications during 2015-2016. Factor A was different tribenuron methyl concentrations including 5, 10, 20, 30 and $40 \mathrm{~g}$ a.i ha ${ }^{-1}$ applied to common lambsquarters control. Factor B was included castor oil (Ricinus communis L.), canola oil (Brassica napus L.) and 
emulsifiable oil citogate (a non-ionic surfactant, 100\% alkyl aryl polyglycol ether) at 0.1 and $0.2 \%$ (v/v). Herbicide was sprayed at 3-4 leaf stages by using a sprayer equipped with a Flat-fan nozzle, delivering $300 \mathrm{~L} / \mathrm{ha}^{-1}$ spray solution at $250 \mathrm{kPa}$. Thirty days after spraying, the number of survived plants per pot and dry biomass (dried at $70{ }^{\circ} \mathrm{C}$ for 48 hours) was recorded. The response of dry biomass (U) to herbicides dose (z) was assumed by a log-logistic model (Equation 1) that was described by (Nielsen et al., 2004):

$$
\mathrm{Uij}=\mathrm{C}+\frac{\mathrm{D}-\mathrm{C}}{1+\exp \left[\mathrm{bi}\left(\log (\mathrm{Zij})-\log \left(\mathrm{ED} \mathrm{EO}_{\mathrm{i}}\right)\right)\right]}
$$

Where Uij denotes the fresh or dry biomass at the $\mathrm{j}$ th dose of the $\mathrm{i}$ th herbicide preparation; $\mathrm{D}$ and $\mathrm{C}$ denote the upper and lower limit of the fresh or dry biomass at zero and at infinite doses; $\mathrm{ED}_{50 \mathrm{i}}$ denotes the required dose of herbicide, $\mathrm{i}$, to give $50 \%$ common lambsquarters control; and $b_{i}$ is proportional to the slope of the curve around the ED50i. The logistic response-dose model was fitted to the experimental data. Theoretically, whether the response curves are parallel or not, horizontal displacement between curves described by relative potency (Equation 2):

$$
R P=\frac{\mathrm{ED}_{\operatorname{sof}}}{\mathrm{ED}_{\operatorname{sinf}+y}}
$$

Where $\mathrm{ED}_{50 \mathrm{f}}$ denotes the $\mathrm{ED}_{50}$ of herbicide formulation alone; and $\mathrm{ED}_{50 \mathrm{f}+\mathrm{v}}$ denotes the $\mathrm{ED}_{50}$ of herbicide formulation along with each adjuvant. If $\mathrm{R}=1$, addition of adjuvants would not have any effect on herbicide response. But if $\mathrm{R}$ was higher or lower than 1 , the herbicide accompanied by adjuvant would be more or less potent than herbicide alone, respectively. The data was subjected to analysis of variance using the MSTAT-C software. Mean comparisons were performed using Duncan Multiple Range Test (DMRT) at 0.05 .

\section{Results}

The results showed that increasing in tribenuron methyl concentration up to $40 \mathrm{~g}$ a.i ha-1 enhanced its efficacy (Table 1). This herbicide controlled weed effectively at higher doses (40 g a.i ha-1). When tribenuron methyl was combined with citogate and vegetable oils, common lambsquarters control was considerably increased consequently. All adjuvantadded to herbicide showed superior performance in reducing the dry weight of common lambsquarters (Table 1). Citogate was the most effective adjuvant as its addition to tribenuron methyl at $40 \mathrm{~g}$ a.i ha-1 led to the highest control of common lambsquarters.

Table 1. Effects of tribenuron methyl with and without adjuvants on common lambsquarters dry weight $\left(\mathrm{g} /\right.$ pot $\left.^{-1}\right)$

\begin{tabular}{cccccccc}
\hline $\begin{array}{c}\text { Herbicide Rate } \\
\left.\text { (g a.i ha }^{-1}\right)\end{array}$ & \multirow{2}{*}{ No Adjuvants } & \multicolumn{2}{c}{ Citogate } & \multicolumn{2}{c}{ Canola oil } & \multicolumn{2}{c}{ Castor oil } \\
& & $\mathbf{0 . 1}$ & $\mathbf{0 . 2}$ & $\mathbf{0 . 1}$ & $\mathbf{0 . 2}$ & $\mathbf{0 . 1}$ & $\mathbf{0 . 2}$ \\
\hline 5 & $2.55^{\mathrm{a}^{*}}$ & $2.15^{\mathrm{a}}$ & $1.80^{\mathrm{a}}$ & $2.35^{\mathrm{a}}$ & $2.05^{\mathrm{a}}$ & $2.25^{\mathrm{a}}$ & $1.95^{\mathrm{a}}$ \\
10 & $2.30^{\mathrm{b}}$ & $1.50^{\mathrm{b}}$ & $1.15^{\mathrm{b}}$ & $1.80^{\mathrm{b}}$ & $1.31^{\mathrm{b}}$ & $1.72^{\mathrm{b}}$ & $1.23^{\mathrm{b}}$ \\
20 & $1.90^{\mathrm{c}}$ & $0.84^{\mathrm{c}}$ & $0.38^{\mathrm{c}}$ & $1.05^{\mathrm{c}}$ & $0.60^{\mathrm{c}}$ & $0.95^{\mathrm{c}}$ & $0.51^{\mathrm{c}}$ \\
30 & $1.30^{\mathrm{d}}$ & $0.11^{\mathrm{de}}$ & $0^{\mathrm{d}}$ & $0.28^{\mathrm{d}}$ & $0^{\mathrm{d}}$ & $0.22^{\mathrm{d}}$ & $0^{\mathrm{d}}$ \\
40 & $0.6^{\mathrm{e}}$ & $0^{\mathrm{e}}$ & $0^{\mathrm{d}}$ & $0^{\mathrm{e}}$ & $0^{\mathrm{d}}$ & $0^{\mathrm{e}}$ & $0^{\mathrm{d}}$ \\
\hline
\end{tabular}

* Treatment means within each column followed by the same letter do not differ significantly at the $5 \%$ level 
The ED $\mathrm{E}_{50}$ and $\mathrm{ED}_{90}$ values of tribenuron methyl were significantly reduced and the Relative Potency (RP) values were significantly increased when citogate and vegetable oils were added to this herbicide (Table 2). These results showed that the adjuvants enhanced the efficacy of tribenuron methyl. The $\mathrm{ED}_{50}$ and $\mathrm{ED}_{90}$ measured parameters estimated by doseresponse model based on common lambsquarters dry weight for tribenuron methyl without adjuvant were 21.24 and $79.86 \mathrm{~g}$ a.i ha-1, respectively (Table 2). Based on the ED 50 and ED9o values given in Table 2, all three adjuvants considerably improved the efficiency of tribenuron methyl. Based on $\mathrm{ED}_{50}$ values, the lowest effect was observed in Canola oil and the highest was obtained from citogate.

Table 2. Measured $\mathrm{ED}_{50}$ and $\mathrm{ED}_{90}$ doses of tribenuron methyl alone and with the presence of adjuvants in the control dry weight of common lambsquarters

\begin{tabular}{cccc}
\hline Experimental Treatments & ED $_{\mathbf{5 0}}$ (ga.i ha-1 $^{\mathbf{1}}$ ) & $\mathbf{E D}_{\mathbf{9 0}}$ (ga.i ha-1 $^{\mathbf{1}}$ ) & $\begin{array}{c}\text { Relative Potency } \\
\text { (RP) }\end{array}$ \\
\hline tribenuron methyl alone & 21.24 & 79.86 & 1 \\
tribenuron methyl + citogate (\% 0.1) & 15.25 & 22.90 & 1.39 \\
tribenuron methyl + citogate (\% 0.2) & 11.48 & 23.79 & 1.85 \\
tribenuron methyl + canola oil (\% 0.1) & 17.17 & 35.10 & 1.23 \\
tribenuron methyl + canola oil (\% 0.2) & 11.81 & 26.74 & 1.80 \\
tribenuron methyl + castor oil (\% 0.1) & 16.50 & 33.80 & 1.28 \\
tribenuron methyl + castor oil (\% 0.2) & 11.65 & 25.50 & 1.82 \\
\hline
\end{tabular}

\section{Discussion}

It was clearly indicated that tribenuron methyl has a vigorous receptivity for surfactants which might be related to weaker penetration of this herbicide into common lambsquarters leaf when applied without adjuvants. In an experiment conducted by (Hunsche and Noga, 2008) it was proved that linseed oils adjuvants showed an increase in efficiency of fungicide mancozeb. With this study, it was shown that the application rate of tribenuron methyl could be reduced when an adjuvant was added. Furthermore, it can be concluded that a higher content of adjuvants affected the herbicidal efficacy in a positive way. Only with an appropriate adjuvant, herbicides can develop their maximum efficacy even at lower than recommended doses.

The fact that modified vegetable oils improve herbicide efficacy is already known and was reviewed by (Gauvarit and Cabanne, 1993). (Giysopoulos et al., 2014) showed that the use of vegetable oil mixtures with Diquat herbicide indicating significant enhancement of Diquat efficacy on grasses. An increased spreading of spray droplets on target plants and an enhanced penetration of active ingredients into leaves seem to be the reasons for the herbicide enhancing action of vegetable oils (Liu, 2004). Since many oil-based adjuvants act well as penetration enhancers, it can be assumed that the addition of these adjuvants can enhance herbicide efficiency (Stock and Briggs, 2000). (Pannacci et al., 2010) reported that the activity of tribenuron methyl was significantly enhanced by three surfactants (Non-ionic surfactant, rapeseed oil and an anionic surfactant). Since it is known that the efficacy of sulfonylureas can be reduced by precipitation within a few hours after application (Russell et al., 2002), an increased performance of those herbicides might have been achieved by the addition of the adjuvants. In this study, the addition of citogate and vegetable oils increased the efficacy of tribenuron methyl in reducing common lambsquarters biomass. The 
improvement on efficacy of tribenuron methyl by these adjuvants may be due to solubilizing, softening or disordering nature of cuticular waxes by the methylated seed oils (Hazen, 2000). Also this is proved that the application of adjuvants could improve the permeability of the herbicide active ingredient (Johnson et al., 2002) which provides an opportunity to reduce herbicide application dose (Zabkiewicz, 2000). It seems that the tested adjuvants led to more cuticular penetration and stomata infiltration and subsequently, allowed better tribenuron methyl absorption and translocation.

All three adjuvants increased considerably the efficiency of tribenuron methyl compared with herbicide alone. (Mehdizadeh and Alebrahim, 2015) found the increased efficacy of sulfosulfuron herbicide to control Phalaris minor by using citogate and different vegetable oil adjuvants. (Rashed-Mohassel et al., 2011) reported that reduction in the surface tension of herbicide solution by the vegetable oils. Therefore, this is an important factor to atomize herbicide droplets and allow remaining it on foliage (Ejim et al., 2007). Also an increase in the penetration dose of active ingredient via disordering of the cuticular waxes is a more important factor in improving the efficiency of herbicides (Rashed-Mohassel et al., 2011). Other researchers have demonstrated that the vegetable oils improved weed control by 2,4-D, phenmedipham (Muller et al., 2002), glyphosate (Gauvrit et al., 2007), metoxuron, sethoxydim, and quizalofop (Ruiter et al., 1997). Vegetable oils such as castor and canola oil probably disrupt and solubilize cuticular waxes (Zabkiewicz, 2000) and consequently, facilitate the penetration of the active ingredient (McMullan and Chow, 1993). The benefits of using these oils (e.g., castor and canola) in enhancing the foliage activity of herbicides have been well documented (Bunting et al., 2004). (Sharma and Singh, 2000) have shown that an increase in the permeability of the herbicide through disordering the cuticular waxes is a more important factor than reduction the surface tension of herbicide droplets in improving the foliar activity of glyphosate on Bidens frondosa and Panicum maximum. Therefore, these results emphasize the dependency of adjuvant performance on herbicide properties and plant species. Selecting proper adjuvants for each herbicide is a key factor in chemical weed management because this factor reduces herbicide rate which is a main research priority. Citogate and vegetable oils compared to mineral oils have any phytotoxic effect on plants and decomposed rapidly in the environment rather than (Cabanne et al., 1999).

\section{Conclusion}

According to our results it could be concluded that the application of these adjuvants could be an efficient method for optimizing herbicide performance on contorting of common lambsquarters. Citogate was the most effective adjuvant as its addition to tribenuron methyl at $40 \mathrm{~g}$ a.i ha-1 led to the highest control of common lambsquarters. So, the use of citogate and vegetable oils seems to be an efficient alternative to other commonly used synthetic adjuvants. This research showed the most performance when vegetable oil based adjuvants was mixed with the tribenuron methyl herbicide.

\section{Acknowledgements}

Authors acknowledged Dr. Soufia Ardestani for her valuable comments and assistance.

\section{Conflict of interest}

The authors declare that there is no conflict of interest. 


\section{References}

Asad, M, Mahmood, Z, Mudassar, M, Arshad, A, Raza, MU, Anum, W. (2019). Bio-economic assessment of non-chemical weed management strategies in minor crops: A review on weed research issues, challenges, and opportunities in Pakistan. J. Res. Weed Sci., 2:127-140.

Bunting, JA, Spragueand, CL, Riechers, DE. (2004). Proper adjuvant selection for foramsulfuron activity. Crop Prot., 23:361-366.

Cabanne, F, Gaudry, J, Streibig, JC. (1999). Influence of alkyl oleates on efficacy of phenmedipham applied as an acetone: water solution on Galium aparine. Weed Res., 39:57-67.

Calore, RA, Ferreira, MC, Rodrigues, NL, Otuka, AK. (2015). Distribution pattern, surface tension and contact angle of herbicides associated to adjuvants on spraying and control of Ipomoea hederifolia under rainfall incidence. Eng. Agricola., 35:756-768.

Ejim, CE, Fleck, BA, Amirfazl, A. (2007). Analytical study for atomization of biodiesels and their blends in a typical injector: surface tension and viscosity effects. Fuel, 86:1534-1544.

Gauvrit, C, Muller, T, Milius, A, Trouve, G. (2007). Ethoxylated rapeseed oil derivatives as nonionic adjuvants for glyphosate. Pest. Manag. Sci., 63:707-713.

Gauvrit, C, Cabanne, F. (1993). Oils For Weed Control: Uses and Mode of Action. Pest. Sci., 37:147-153.

Gitsopoulos, TK, Damalas, CA, Georgoulas, I. (2014). Improving diquat efficacy on grasses by adding adjuvants to the spray solution before use. Planta Daninha, 32:355-360.

Hazen, JL. (2000). Adjuvants terminology, classification and chemistry. Weed Technol., 14:773784.

Hunsche, M, Noga, GJ, Schmitz-Eiberger, M. (2008). Seed Oil Ethoxylate Adjuvants and Their Influence on Retention and Rainfastness of the Contact Fungicide Mancozeb. Acta Hortic., 772:403-406.

Johnson, HE, Hazen, JL, Penner, D. (2002). Citric ester surfactants as adjuvants with herbicides. Weed Technol., 16:867-872.

Keller, M, Böhringer, N, Möhring, J, Rueda-Ayala, V, Gutjahr, C, Gerhards, R. (2014). Long-term changes in weed occurrence, yield and use of herbicides in maize in south-western Germany, with implications for the determination of economic thresholds. Weed Res., 54:457-466.

Khammassi, M, Chaabane, H, Souissi, T. (2018). The occurrence of resistance to ALS and ACCase-inhibiting herbicides ryegrass (Lolium rigidum Gaudin) in Bizerte region. J. Res. Weed Sci., 1:110-122.

Kočárek, M, Kodešová, R, Sharipov, U, Jursík, M. (2018). Effect of adjuvant on pendimethalin and dimethenamid-P behaviour in soil.J. Hazard Mater., 345:266-274. 
Kraehmer, H, Laber, B, Rosinger, C, Schulz, A. (2014). Herbicides as Weed Control Agents: State of the Art: I. Weed Control Research and Safener Technology: The Path to Modern Agriculture. Plant Physiol., 166:1119-1131.

Lian, JL, Ren, LS, Zhang, C, Yu, CY, Huang, Z, Xu, AX, Dong, JG. (2019). How exposure to ALSinhibiting gametocide tribenuron-methyl induces male sterility in rapeseed. BMC Plant Biol., 19:124.

Liu, Z. (2004). Effect of surfactants on foliar uptake of herbicides-A Complex Scenario. Coll. Surf, B Biointerfaces., 35:149-153.

Marcinkowska, K, Praczyk, T, Łęgosz, B, Biedziak, A, Pernak, J. (2018). Bio-ionic Liquids as Adjuvants for Sulfonylurea Herbicides. Weed Sci., 66:404-414.

McMullan, PM, Chow, PN. (1993). Efficacious adjuvants for fluazifop or sethoxydim in flax and canola. Crop Prot., 12:544-548.

Mehdizadeh, M, Alebrahim, MT. (2015). Effect of Some Adjuvants application on Enhancing Sulfosulfuron Herbicide Performance On Phalaris minor-Poaceae. Azarian J. Agricul., 2:7-11.

Mehdizadeh, M, Izadi Darbandi, E. (2015). An efficient strategy on enhancing herbicide performance with adjuvant application. J. Agricul. Res., 53:547-554.

Mehdizadeh, M. (2016). Effect of Pesticide Residues on Agricultural Food Production; A Case Study: Sensitivity of Oilseed Rape to Triasulfuron Herbicide Soil Residue. MOJ Food Process. Technol., 2:53-54.

Mehdizadeh, M, Alebrahim, MT, Roushani, M, Streibig, JC. (2016). Evaluation of four different crops' sensitivity to sulfosulfuron and tribenuron methyl soil residues. Acta Agricul. Scandin., Section B-Soil Plant Sci., 66:706-713.

Mehdizadeh, M, Gholami-Abadan, F. (2018). Negative Effects of Residual Herbicides on Sensitive Crops: Impact of Rimsulfuron Herbicide Soil Residue on Sugar beet. J. Res. Weed Sci., 1:1-6.

Muller, T, Brancq, B, Milius, A. (2002). Ethoxylated rapeseed oil derivatives as novel adjuvants for herbicides. Pest Manag. Sci., 58:1243-1249.

Niedobová, J, Skalský, M, Ouředníčková, J, Michalko, R, Bartošková, A. (2019). Synergistic effects of glyphosate formulation herbicide and tank-mixing adjuvants on Pardosa spiders. Environ. Pollut., 249:338-344.

Nielsen, OK, Ritz, C, Streibig, JC. (2004). Nonlinear mixed-model regression to analyze herbicide dose-response relationships. Weed Technol., 18:30-37.

Pannacci, P, Mathiassen, SK, Kudsk, P. (2010). Effect of adjuvants on the rainfastness and performance of tribenuron-methyl on broad-leaved weeds. Weed Biol. Manag., 10:126-131.

Powles, SB, Yu, Q. (2010). Evolution in action: plants resistant to herbicides. Annu. Rev. Plant Boil., 61:317-47. 
Rashed-Mohassel, MH, Aliverdi, A, Rahimi, S. (2011). Optimizing dosage of sethoxydim and fenoxaprop-p-ethyl with adjuvants to control wild oat. Indust. Crop Prod., 34:1583-1587.

Rizwan, M, Tanveer, A, Khaliq, A, Abbas, T, Ikram, NA. (2018). Increased foilar activity of isoproturon+tribenuron and pyroxsulam against little seed canary grass and field bindweed by proper adjuvant selection in wheat. Plant. Daninha, 36:018166733.

Ruiter, HD, Uffing, AJM, Meinen, E. (1997). Influence of emulsifiable oils and emulsifier on the performance of phenmedipham, metoxuron, sethoxydim, and quizalofop. Weed Technol., 11:290-297.

Russel, MH, Saladini, MH, Lichtner, F. (2002). Sulfonylurea Herbicides. Pestic Outlook, 13:166173.

Saini, H, Bassi, PK, Spencer, MS. (1986). Use of Ethylene and Nitrate to Break Seed Dormancy of Common Lambsquarters (Chenopodium album). Weed Sci., 34:502-506.

Sharma, SD, Singh, M. (2000). Optimizing foliar activity of glyphosate on Bidens frondosa and Panicum maximum with different adjuvant types. Weed Res., 40:523-533.

Singh, AK, Pandey, AK. (2019). Standardization of Various Parameters for Mycoherbicidal metabolites production from Fusarium sp. FGCCW\#16 for Parthenium hysterophorus Management. J. Res. Weed Sci., 2:203-215.

Stock, D, Briggs, G. (2000). Physicochemical Properties of adjuvants: Values and applications. Weed Technol., 14:798-806.

Underwood, AL. (2000). Adjuvant trends for the new millennium. Weed Technol., 14:765-772.

Widiyat, D, Sumekar, Y, Wahyudin, A, Yuwariah, Y, Farida, C. (2019). Effect of various dosage of ammonium glufosinate herbicide on suppressing weeds and growth and yield of corn. J. Res. Weed Sci., 2:90-102.

Zabkiewicz, JA. (2000). Adjuvants and herbicidal efficacy present status and future prospects. Weed Res., 40:139-149.

How to cite this article: Mohammad Mehdizadeh, Zoleikha Mehdizadeh, Zahra Baghaeifar. Efficacy Evaluation of Tribenuron Methyl Herbicide by Using Different Adjuvants for Common Lambsquarters (Chenopodium album L.) Control. International Journal of Advanced Biological and Biomedical Research, 2020, 8(1), 1-8. Link: http://www.ijabbr.com/article 36168.html 